\title{
The HIV-1 viral protein Tat modulates glutamate and GABA exocytosis from human and mouse neocortical nerve endings by acting at different binding sites
}

Maria Summa, Paolo Severi, Aldamaria Puliti, Maurizio Raiteri, Anna Pittaluga*

From $16^{\text {th }}$ International Symposium on HIV and Emerging Infectious Diseases

Marseille, France. 24-26 March 2010

\section{Background}

Central Nervous System (CNS) disorders often accompany the acquired immunodeficiency syndrome (AIDS) and are typified by neuropsychiatric symptoms, such as cognitive and motor impairments, sometimes paralleled by neuropathological hallmarks. Collectively, these events are referred to as HIV-1 associated dementia (HAD). Before the advent of the Highly Active Antiretroviral Therapy (HAART), about $20 \%$ of adult patients, but as many as $40 \%$ of children/adolescent infected subjects developed HAD. Nowadays, in the era of HAART, the prevalence of HAD has decreased, but a more subtle form of disorder, referred to as Minor Cognitive Motor Disorder (MCMD), has emerged in about $20 \%$ of symptomatic HIV-1 seropositive patients, including those receiving HAART. This work was aimed at investigating the impact of the HIV-1 viral protein Tat on central neurotransmission since this protein has been proposed as one of the viral component involved in the onset of central neuropsychiatric symptoms.

\section{Methods}

The approach used was the up-down superfusion of purified synaptosomes isolated from human neocortical specimens removed during neurosurgery from consenting patients suffering of brain tumours. Experiments were also carried out by using mouse purified synaptosomes or slices in an attempt to propose an animal model suitable to investigate Tat-induced modification to central nervous system. Functional studies were paralleled by biochemical investigation on the existence of receptor protein potential involved in the effects observed and changes to second messenger production.

\section{Results}

Human immunodeficiency virus-1 (HIV-1)-encoded transactivator of transcription (Tat) potentiated the depolarization-evoked exocytosis of [3H]D-aspartate ([3H]D-ASP) from human neocortical terminals. The metabotropic glutamate (mGlu) 1 receptor antagonist CPCCOEt prevented this effect, whereas the mGlu5 receptor antagonist MPEP was ineffective. Western blot analysis showed that human neocortex synaptosomes possess mGlu1 and mGlu5 receptors. Tat potentiated the $\mathrm{K}+-$ evoked release of $[3 \mathrm{H}]$ D-ASP or of endogenous glutamate from mouse neocortical synaptosomes in a CPCCOEt-sensitive, MPEP-insensitive manner. Deletion of mGlu1 receptors (crv4/crv4 mice) or mGlu5 receptors (mGlu5-/-mouse) silenced Tat effects, suggesting that mGlu1 and mGlu5 receptors are co-express on glutamatergic terminals. Tat enhanced inositol 1,4,5-trisphosphate production in human and mouse neocortical synaptosomes, consistent with the involvement of group I mGlu receptors. Tat inhibited the $\mathrm{K}+$-evoked release of $[3 \mathrm{H}] \mathrm{GABA}$ from human synaptosomes and that of endogenous GABA or [3H]GABA from mouse nerve terminals; the inhibition was insensitive to CPCCOEt or MPEP. In mouse neocortical slices, Tat facilitated the K+and the veratridine-induced release of [3H]D-ASP in a CPCCOEt-sensitive manner and was ineffective in crv4/crv4 mouse slices.

* Correspondence: pittalug@pharmatox.unige.it

DIMES, Genova, Italy 


\section{Discussion}

These observations are relevant to the comprehension of the pathophysiological effects of Tat in central nervous system and may suggest new potential therapeutic approaches to the cure of HIV-1 associated dementia.

This work was supported by grants from Italian Ministero dell'Istruzione, dell'Università e della Ricerca Scientifica [Projects n. 200728AA57_002 (A.P.) and 2007YYL5J9_004 (M.R.)], from University of Genoa 'Progetto Ricerca Ateneo' (A.P., M.R.) and from Istituto Superiore di Sanità (Programma Nazionale di Ricerca sull'AIDS: Progetto "Patologia, Clinica e Terapia dell'AIDS, M.R.).

Published: 11 May 2010

doi:10.1186/1742-4690-7-S1-P5

Cite this article as: Summa et al:: The HIV-1 viral protein Tat modulates glutamate and GABA exocytosis from human and mouse neocortical nerve endings by acting at different binding sites. Retrovirology 20107 (Suppl 1):P5.

Submit your next manuscript to BioMed Central and take full advantage of:

- Convenient online submission

- Thorough peer review

- No space constraints or color figure charges

- Immediate publication on acceptance

- Inclusion in PubMed, CAS, Scopus and Google Scholar

- Research which is freely available for redistribution

Submit your manuscript at www.biomedcentral.com/submit 